Original Research Paper

\title{
Flavonoids and Antimicrobial Properties of Begonia fischeri var. palustris in vitro Plantlets
}

\author{
${ }^{1}$ Evgeniya A. Karpova, ${ }^{1}$ Alexandra Yu. Nabieva, ${ }^{1}$ Tatiana D. Fershalova, \\ ${ }^{2}$ Yuliya L. Yakimova and ${ }^{1}$ Nataliya V. Tsybulya \\ ${ }^{I}$ Central Siberian Botanical Garden of the Siberian Branch of Russian Academy of Sciences (CSBG RAS), Novosibirsk, Russia \\ ${ }^{2}$ State Research Center of Virology and Biotechnology VECTOR, Federal Service for Surveillance on Consumer Rights \\ Protection and Human Wellbeing, Koltsovo, Novosibirsk region, Russia
}

Article history

Received: 13-12-2018

Revised: 16-01-2019

Accepted: 28-01-2019

Corresponding Author:

Evgeniya A. Karpova,

Central Siberian Botanical

Garden Siberian Branch of

Russian Academy of Sciences,

Novosibirsk, Russia

E-mail: karpova@csbg.nsc.ru
Abstract: The objective of this study was to design a protocol of the successful establishment of plants of Begonia fischeri var. palustris obtained in the in vitro seeds culture, to evaluate flavonoid content and antimicrobial properties of in vitro plantlets. The significant increase of percentage of seed germination $(92.5 \%)$ was recorded in the half strength MS medium and $1 \%$ agar medium $(83.3 \%$ ) in comparison with $50-60 \%$ in greenhouse conditions. Flavonoid composition of the leaves of in vitro plantlets and greenhouse stock plants had no substantial differences. Significant differences $(\mathrm{p}<0.05)$ were not found between flavonoid contents of the leaves (13.6 and $15.5 \mathrm{mg} \cdot \mathrm{g}^{-1}$ of Dry Weight (DW), respectively). Aqueous ethanol extracts of plants showed antimicrobial effects against reference strains of Bacillus subtilis, Streptococcus pyogenes and Staphylococcus aureus. Concentration of flavonoids in acetone and ethanol extracts of exudative compounds of the leaves of in vitro plantlets was 0.02 and $2.0 \mathrm{mg} \cdot \mathrm{g}^{-1} \mathrm{DW}$, respectively. Our results indicated that this protocol can be used for the production of a large number of plants of $B$. fischeri var. palustris with rich flavonoid composition and high quantities of flavonoids, including exudative compounds, with healing and air cleaning properties.

Keywords: Antimicrobial Properties, Begonia fischeri var. palustris, Flavonoids, Indoor Plant Design, in vitro Seed Germination, Metabolic Engineering

\section{Introduction}

Begonia fischeri Schrank var. palustris (Hartw. ex Benth.) Irmsch. (section Begonia) is ornamental shrublike plant with a vigorous growth. It is implemented in ornamental gardening in greenhouses throughout the world, including Siberia. Its natural habitat is the Atlantic coastal forest in Brazil. It grows mostly in marshy places and forms large thickets under the shadow of forest canopy. Flowering continues throughout the year.

Vegetative multiplication of the species by means of traditional cultivation techniques seems to be highly laborious. In vitro raising of many begonias is an alternative efficient system widely used by commercial nurseries and institutes for rapid plants propagation, germplasm conservation, elimination of pathogens and for phytochemical screening of medicine-useful compounds (Murugan et al., 2016). The seed populations in vitro can be stored for a long time lacking the problems of bacterial or fungal infections ordinarily associated with long-term maintenance of Begonia clonal stock.

In addition to high decorative, B. fischeri var. palustris contains phenolic compounds, including flavonoids and have prospects for use as medicinal (Karpova et al., 2018). Nowadays, a large number of studies are devoted to antimicrobial activity of plants. Flavonoid-rich plant extracts from many species were shown to possess antibacterial and antifungal activity (Cushnie and Lamb, 2005; Xie et al., 2015).

Despite the increased attention to the biology and pharmacognosy of the genus Begonia in the world, data on the chemical composition and biological activity of the species of the genus are still sparse. Antimicrobial properties of the extracts of several species ( $B$. erythrophylla, $B$. heracleifolia, $B$. semperflorens, $B$. fuchsioides, B. picta and B. malabarica) were investigated (Frei et al., 1998; Ramesh et al., 2002; Nisha et al., 2016). 
Flavonoids composition of the genus Begonia is fragmentary studied. In leaves and flowers, luteolin, luteolin 7-O-glucoside (cynaroside), quercetin, rutin, quercitrin, isoquercitrin, quercetin 3-O-xyloside, kaempferol 3-O-glucoside (astragalin), kaempferol rutinoside, kaempferol 3-methyl ether (isokaempferide) and its 7-O-glucoside, quercetin 3-methyl ether and its 7O-glucoside, quercetin 3, 7, 3'-trimethyl ether and gossypetin 3,7,8,3'-tetramethyl ether, glycosyl flavones (vitexin, isovitexin and orientin) were found. In anthocyanin composition, glycosides of cyanidin, pelargonidin and peonidin were detected (Chirol and Jay, 1995; Harborne and Williams, 2001; Saffidine et al., 2017). There are very few reports concerning the concentrations of flavonoids in in vitro derived plants (Murugan et al., 2016) and the chemical content of $B$. fischeri var. palustris (Karpova et al., 2018).

Representatives of the genus Begonia are widely presented in the plant design indoor. In this regard, it is important to assess the composition of the surface exudative compounds of the leaves as air cleaners. At this moment, exudative constituents of the leaves, located on the leaf surface, are extensively investigated (Muravnik et al., 2016). Meanwhile, these compounds of representatives of the genus Begonia are at the very beginning of study (Ensemeyer and Langhammer, 1982).

The objective of this study was to design a protocol for the plant production using in vitro seeds culture and to evaluate flavonoid content and antimicrobial properties of in vitro plantlets $B$. fischeri var. palustris. This includes initiation and inoculation of aseptic cultures of seeds, examination of the effect of different media on the germination rate of $B$. fischeri var. palustris.

\section{Materials and Methods}

\section{Seed Sterilization and Germination}

The mature fruits of $B$. fischeri var. palustris were harvested three months after hand pollination. Seed capsules were surface disinfected with $70 \%$ ethanol for 1 min, followed by immersion in $0.1 \%$ solution of $\mathrm{HgCl}_{2}$ for $10 \mathrm{~min}$ and finally rinsed thoroughly with three times in sterile distilled water.

The nutritious media were enriched by $2.5 \%$ sucrose and solidified with $0.6 \%$ agar. The $\mathrm{pH}$ in all variants of media were adjusted to 5.8 prior to autoclaving at $121^{\circ} \mathrm{C}$ and $103.4 \mathrm{kPa}$ for $20 \mathrm{~min}$. The cultures were incubated at $22 \pm 2{ }^{\circ} \mathrm{C}$ with light/dark $16 / 8$ hours photoperiod provided by white fluorescent tubes (1500 lx).

Seeds were inoculated onto four variants of imbibition media: $1.0 \%$ agar, $1 / 2$ MS (half strength MS salts) (Murashige and Skoog, 1962), MS and MS supplemented with $0.5 \mathrm{mg} \cdot \mathrm{L}^{-1} \quad$ 6-benzylaminopurine (BAP) and $0.3 \mathrm{mg} \cdot \mathrm{L}^{-1}$ of $\alpha$-Naphthaleneacetic Acid (NAA). In each flask, $100 \pm 5$ seeds were inoculated, using the modified technique, where the disinfected seeds were firstly scattered on a sterile paper and transferred individually to the agar medium with a dissecting needle. In every variant of medium, three replicates were fulfilled.

B. fischeri var. palustris seed germination was defined here as hypocotyl emergence (1/3 the length of the seed size). Germination was monitored every day for until no further germination was recorded. Final germination percentage (FG) and Mean Daily Germination (MDG) were calculated using the formulas given below:

$$
F G=n / N \times 100 \%, M D G=F G / D
$$

Where:

$n=$ The number of germinated seeds

$N=$ The total number of seeds

$D=$ The number of days to final germination

\section{Plant Growth Conditions in Greenhouse}

Hardened in vitro plantlets of B. fischeri var. palustris after transfer from sterile substrate grew in greenhouse on soil mixture consisted of the rotted leaf litter mixture with river sand $(1: 1)$ in the greenhouse conditions (temperature $20-23^{\circ} \mathrm{C}$, humidity $50-60 \%$, illumination 40-60 $\mu \mathrm{mol} \mathrm{m} \mathrm{s}^{-2}$ ).

Simultaneously with the beginning of the seed germination in vitro, B. fischeri var. palustris seeds gathered from greenhouse stock plants were sown directly in greenhouse on the same soil mixture under the similar greenhouse conditions (greenhouse plants). Further, experimental design consisted in comparison of the greenhouse plants and in vitro plantlets.

\section{Flavonoid Identification and Quantification}

The greenhouse-grown plants and in vitro plantlets of $B$. fischeri var. palustris were grown in the composition of "Collections of living plants indoors and outdoors" USU 440534 of Central Siberian Botanical Garden, Siberian Branch of Russian Academy of Sciences, Novosibirsk, Russian Federation (CSBG SB RAS) under greenhouse conditions with a temperature of $+15-25 \mathrm{C}^{0}$, humidity of $30-60 \%$ and illumination of $40-60 \mu \mathrm{mol} \mathrm{m}^{-2} \mathrm{~s}^{-1}$.

Leaves from ten of greenhouse plants (L) and ten in vitro plantlets (LR) were collected for detection of flavonoids in the beginning of generative state (at 60th day after transfer ex vitro).

For detection of flavonoids, precisely weighed samples of fresh plant material $(0.5 \mathrm{~g})$ were exhaustively extracted with an ethanol: water mixture $(70: 30, \mathrm{v} / \mathrm{v})$ in a water bath at $60-70^{\circ} \mathrm{C}$. Aqueous ethanol crude extract was filtered, diluted with the ethanol:water mixture $(70: 30, \mathrm{v} / \mathrm{v})$ up to the volume of $25 \mathrm{~mL}$ in a graduated flask and used for quantification of flavonoids and evaluation of antimicrobial activity. Dry-weight concentration in the samples was calculated by the gravimetric method. The method was reported in detail previously (Karakulov et al., 2018). 
For studying the exudate flavonoids of the leaves of in vitro plantlets, acetone and ethanol extracts of leaf surface constituents were prepared. For acetone extraction, fresh (not ground) precisely weighed leaves were briefly rinsed with acetone to dissolve the surface constituents (Exudate A). Ethanol extract (Exudate E) was made with analogous wash of fresh leaves with $95 \%$ ethanol. The acetone and ethanol solutions were evaporated to dryness and each residue was dissolved in a small volume of $95 \%$ ethanol. These ethanol extracts were used for quantification of compounds in leaf exudates and for evaluation of antimicrobial activity. Dry-weight concentration in the samples was calculated by the gravimetric method.

The HPLC system for absolute quantification of flavonoids consisted of an Agilent 1200 with a Diode Array Detector (DAD) and the ChemStation software (Agilent Technologies, Santa Clara, CA, USA) for data processing. The chromatographic separation was conducted at $25^{\circ} \mathrm{C}$ on a Zorbax SB-C18 Column $(4.6 \times 150 \mathrm{~mm}, 5 \mu \mathrm{m}$ i.d.) with the Agilent Guard Column Hardware Kit (p.n. 820888-901).

The mobile phase consisted of $\mathrm{MeOH}$ (solvent A) and $0.1 \%$ orthophosphoric acid dissolved in water (solvent B). Separation of glycosides of flavonoids in crude extracts was performed with gradient. The run via gradient was started with a solvent $\mathrm{A}$-solvent $\mathrm{B}$ mixture at 32:68 (v/v) followed by a linear gradient to 33:67 $(\mathrm{v} / \mathrm{v})$ for the first $27 \mathrm{~min}$, then to $46: 64(\mathrm{v} / \mathrm{v})$ from minute 28 to minute 38 , then to $56: 44$ from minute 39 to minute 50 , then to $100: 0$ from minute 51 to minute 54 . The mobile phase was returned to $32: 68(\mathrm{v} / \mathrm{v})$ from minute 55 to minute 56 . The flow rate was set to $1 \mathrm{~mL} \cdot \mathrm{min}^{-1}$. The sample injection volume was $10 \mu \mathrm{L}$ and the absorbance was measured at 210, 255, 270, 290, 325, 340, 360 and $370 \mathrm{~nm}$. The quantification of phenolic compounds was conducted by the external-standard method. Chemical reference standards of quercetin, kaempferol, luteolin, kaempferol rutinoside, vitexin and isovitexin were purchased from Sigma (St. Louis, MO, USA) and hyperoside, isoquercitrin, astragalin were obtained from Fluka (Fluka, Sigma-Aldrich Chemie GmbH, Munich, Germany). Validation of the analytical procedures was performed in accordance with ICH guidelines (2005).

Anthocyanin content was determined by spectrophotometric method on UV-Vis spectrophotometer "Agilent 8453" (Agilent Technologies, Santa Clara, CA, USA). The concentration of anthocyanins ( $\mathrm{mg} \cdot \mathrm{g}^{-1}$ of dry weight) was calculated using the molar absorbtion coefficient of cyanidin-3-rutinoside in $1 \% \mathrm{HCl}$ in water equal to 28840 . The absorbance of fresh leaves extract (in $1 \% \mathrm{HCl}$ in water) was measured at wavelengths of 529 and $650 \mathrm{~nm}$ (Karpova and Fershalova, 2016).

\section{Evaluation of Antimicrobial Activities}

The disk diffusion method was chosen for preliminary evaluation of the antimicrobial activities of crude extracts and exudates of the greenhouse plants and the in vitro plantlets of $B$. fischeri var. palustris. The strains of American Type Culture Collection were used as reference strains: gram-positive bacteria - Staphylococcus aureus ATCC 25923 (SA), Streptococcus pyogenes ATCC 12344 (SP) and Bacillus subtilis ATCC 6633 (BS); gramnegative bacteria - Escherichia coli ATCC 25922 (EC), Klebsiella pneumonia ATCC 13883 (KP), Enterobacter aerogenes ATCC 35029 (EA), Pseudomonas aeruginosa ATCC 27853 (PA) and Enterococcus faecalis ATCC 19433 (EF) and fungi - Candida albicans ATCC 10231 (CA). Ciprofloxacin (5 $\mu \mathrm{g})$ served as a standard antibacterial agent and itraconazole $(10 \mu \mathrm{g})$ was used as a standard antifungal agent (positive control). Ethanol served as a negative control.

Seven reference strains ( $S$. aureus, $S$. pyogenes, $B$. subtilis, E. coli, E. arerogenes, E. faecalis and $C$. albicans) were selected for the determination of Minimal Inhibitory Concentrations (MICs) of the extracts and the exudates, based on their disc-diffusion susceptibility data. MICs of the leaf extracts of the greenhouse plants (L) and the in vitro plantlets (LR) and the acetone (A) and the ethanol (E) exudates together with ciprofloxacin and itraconazole were determined using the broth microdilution assay (Andrews, 2001). The bacteria reference strains and the strain of $C$. albicans were grown overnight on nutritive agar for microorganisms and on mycobiotic agar (respectively) from Laboratorios Conda and diluted equivalent to a 0.5 McFarland standard (Andrews, 2001). Microtiter plate wells (final total volume of $200 \mu \mathrm{L}$ ), each containing $90 \mu \mathrm{L}$ of Mueller-Hinton (MH) broth were inoculated with $10 \mu \mathrm{L}$ of cell suspension and serial dilutions of the extracts and the exudates $\left(100,50,20,10\right.$ and $\left.5 \mu \mathrm{g} \cdot \mathrm{m} \mathrm{L}^{-1}\right)$ and antimicrobial agents ciprofloxacin $\left(0.025 \mu \mathrm{g} \cdot \mathrm{mL}^{-1}\right.$ to $\left.128 \mu \mathrm{g} \cdot \mathrm{m} \mathrm{L}^{-1}\right)$ and itraconazole $\left(0.008 \mu \mathrm{g} \cdot \mathrm{m} \mathrm{L}^{-1}\right.$ to 4 $\left.\mu \mathrm{g} \cdot \mathrm{m} \mathrm{L}^{-1}\right)$. Test range of itraconazole was established in accordance with European Committee for Antimicrobial Susceptibility Testing (Arendrup et al., 2017). The plates were incubated at $30^{\circ} \mathrm{C}$ for $24 \mathrm{~h}$ without shaking. The negative control wells contained $\mathrm{MH}$ broth only and the positive control wells contained the respective cell suspensions with no plant extract (exudates)/antimicrobial agents added. This was done in triplicate (Andrews, 2001). The MIC was the lowest concentration of antimicrobial agent, which inhibited visible growth of organism.

\section{Statistical Analysis}

All the data were expressed as mean \pm standard error (SE) of three replicates \%. The data were analyzed using one-way analysis of variance (ANOVA) and means were compared using Duncan multiple range test. The values of $\mathrm{P}<0.05$ were considered significant. 


\section{Results}

B. fischeri var. palustris seed germination in the greenhouse conditions generally occurred within 3 weeks and final germination percentage (FG) was in the range of $50-60 \%$.

When evaluating the final germination percentage of the species in vitro, significant differences were observed between all the variants tested. The highest percentages of seed germination ( $92.5 \%$ ) were recorded in the half strength MS basal medium ( $1 / 2$ MS) followed by $1 \%$ agar medium (83.3\%). In the tissue culture conditions, germination rate of seeds was the highest in Var.1: seed emergence occurred within 11 days (Table 1).

In Var. 2 and 2A the germination rate was poor, it took more than 15 days for seed emergence and seedlings developed more slowly (Fig. 1).
Half strength MS medium produced optimal results for the B. fischeri var. palustris seedling development suggesting that this medium was the most suitable for the germination of the species.

After 30 days, all the germinated seeds were transferred to a sterilized medium containing fullstrength MS salts, $2 \%$ sucrose and $0.6 \%$ agar. For acclimatization, plantlets with well-developed roots and shoots (Fig. 1c) were removed from the tissue culture, transferred to small plastic pots and exhibited $85 \%$ survival in the mixture of sterile garden soil and river sand $(1: 1)$. Seedlings were incubated in a room condition at $20^{\circ}-22^{\circ} \mathrm{C}$ and $12 \mathrm{~h}$ photoperiod under cool-white light $(40$ $\mu \mathrm{molm} \mathrm{m}^{-2} \mathrm{~s}^{-1}$ ) for 40 days. Then the hardened plantlets, as well as the greenhouse plants, were investigated for antimicrobial activity and flavonoid composition (Fig. 2).

Table 1: Germination of B. fischeri var. palustris in sterile conditions using four different initial medium variants

\begin{tabular}{llll}
\hline Variants of media & Medium composition & Mean daily germination & Final germination \% \\
\hline Var.0 & 1\% agar & $8.2 \pm 0.6 \mathrm{a}$ & $83.3 \pm 2.0 \mathrm{~b}$ \\
Var.1 & $1 / 2 \mathrm{MS}$ & $7.8 \pm 0.5 \mathrm{a}$ & $92.5 \pm 1.5 \mathrm{a}$ \\
Var.2 & $\mathrm{MS}$ & $4.0 \pm 0.1 \mathrm{~b}$ & $64.5 \pm 2.2 \mathrm{c}$ \\
Var. 2 A & $\mathrm{MS}+0.5 \mathrm{mg} \cdot \mathrm{L}^{-1} \mathrm{BAP}+0.3 \mathrm{mg} \cdot \mathrm{L}^{-1} \mathrm{NAA}$ & $3.5 \pm 0.3 \mathrm{~b}$ & $38.4 \pm 0.7 \mathrm{~d}$ \\
\hline
\end{tabular}

*mean \pm SE in columns followed by the same letter do not differ significantly according Duncan test

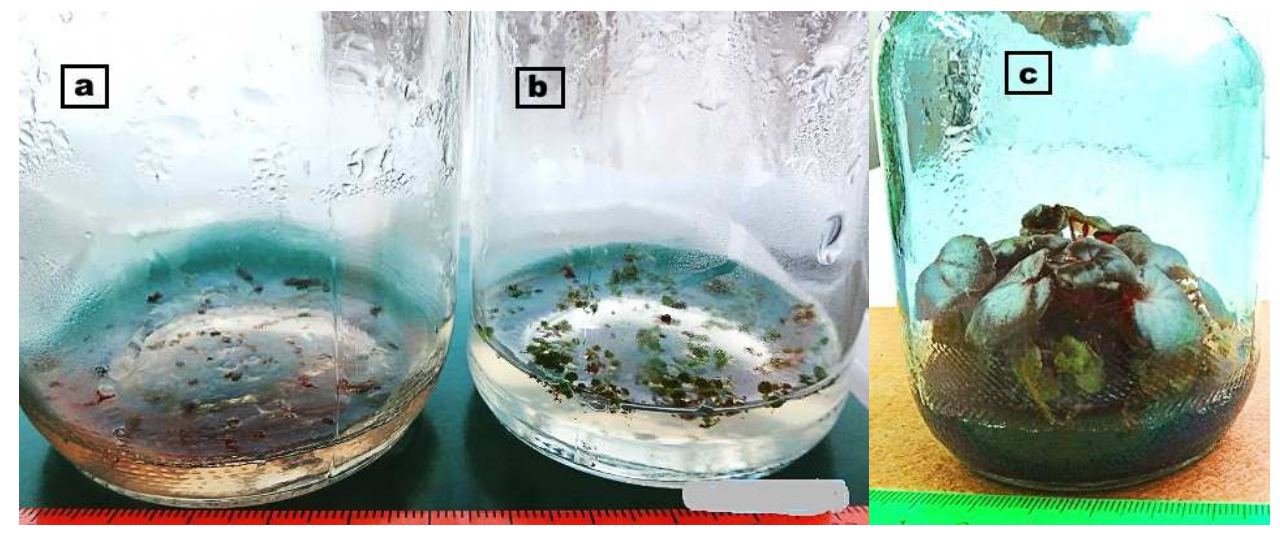

Fig. 1: Developmental stages of B. fischeri var. palustris seedlings grown on the different variants of germination medium (a) Poor seed germination in Var. 2 A observed on 7th day of seeds inoculation (b) Vigorous seed germination in Var.1 (7th day) (c) Well-developed plantlets before the transplantation in ex vitro conditions
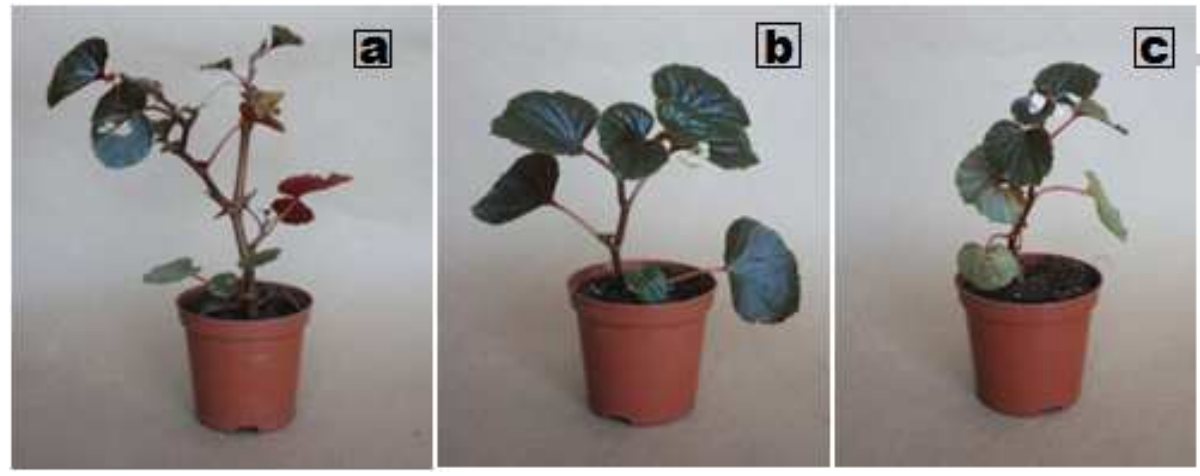

Fig. 2: Greenhouse stock plant (a), hardened in vitro plantlet (b) and greenhouse plant (c) of B. fischeri var. palustris (the age of the plants is 18,4 and 6 months, respectively) 
$\underline{\text { Table 2: Flavonoid composition of the leaves and the leaf exudates of B. fischeri var. palustris and yield of total flavonoids per plant }}$

\begin{tabular}{|c|c|c|c|c|}
\hline \multirow[b]{2}{*}{ Parameter } & \multicolumn{4}{|l|}{ Value } \\
\hline & $\mathrm{La}$ & LR & Exudate A & Exudate E \\
\hline Total phenolic compounds, number & 17 & 18 & 16 & 10 \\
\hline Flavonoids, number & 10 & 9 & 13 & 8 \\
\hline \multicolumn{5}{|l|}{ Concentration, $\mu \mathrm{g} \cdot \mathrm{g}^{-1}$ of dry weight } \\
\hline Orientin & $1320.9 \pm 144.2$ & $1024.5 \pm 88.3$ & $1.0 \pm 0.2(0.10)^{\mathrm{b}}$ & $30.1 \pm 4.2(2.9)$ \\
\hline Vitexin & $524.0 \pm 62.2$ & $\mathrm{Nd}$ & $1.5 \pm 0.1(-)$ & $12.8 \pm 1.5(-)$ \\
\hline Isovitexin & $1115.4 \pm 212.3^{*}$ & $833.0 \pm 54.2$ & $1.9 \pm 0.2(0.23)$ & $\mathrm{Nd}$ \\
\hline Hyperoside & $3051.2 \pm 199.6^{*}$ & $2345.1 \pm 250.2$ & $1.0 \pm 0.1(0.04)$ & $20.2 \pm 3.1(0.86)$ \\
\hline Isoquercitrin & $6818.3 \pm 702.2^{*}$ & $5535.2 \pm 408.6$ & $1.6 \pm 0.2(0.03)$ & $90.0 \pm 8.4(1.63)$ \\
\hline Rutin & $553.6 \pm 308.5^{*}$ & $1107.1 \pm 118.2$ & $0.2 \pm 0.0(0.02)$ & $10.1 \pm 1.2(0.91)$ \\
\hline Astragalin & $211.2 \pm 15.8$ & $222.4 \pm 26.2$ & $0.7 \pm 0.0(0.31)$ & $14.6 \pm 1.6(6.56)$ \\
\hline Kaempferol rutinoside & $218.0 \pm 30.3^{*}$ & $137.0 \pm 15.3$ & $0.7 \pm 0.1(0.51)$ & $\mathrm{Nd}$ \\
\hline Quercetin & $112.4 \pm 27.5^{*}$ & $43.7 \pm 3.9$ & $0.2 \pm 0.0(0.46)$ & $3.5 \pm 0.5(8.01)$ \\
\hline Luteolin & $15.1 \pm 3.2$ & $\mathrm{Nd}$ & $\mathrm{Nd}$ & $\mathrm{Nd}$ \\
\hline Kaempferol & $\mathrm{Nd}$ & $\mathrm{Nd}$ & $0.2 \pm 0.0(-)$ & $\mathrm{Nd}$ \\
\hline Total flavonoids & $15459.0 \pm 2318.5$ & $13636.3 \pm 1295.1$ & $14.3 \pm 1.9(0.10)$ & $438.6 \pm 52.1(3.22)$ \\
\hline $\begin{array}{l}\text { Total phenolic compounds } \\
(9.21)\end{array}$ & $27618.1 \pm 2008.3 *$ & $22024.3 \pm 2234.3$ & $18.7 \pm 2.5(0.08)$ & $2028.9 \pm 21.4$ \\
\hline Anthocyanins & $7211.5 \pm 432.0$ & $7835.0 \pm 728.4$ & $\mathrm{Nd}(-)$ & $214.3 \pm 32.2(2.74)$ \\
\hline Yield of total flavonoids per plant, $g$ & $174.0 \pm 12.2 *$ & $189.1 \pm 13.4$ & $0.2 \pm 0.0$ & $6.1 \pm 0.4$ \\
\hline
\end{tabular}

*Significant differences between L and LR $(\mathrm{p}>0.05)^{\mathrm{a}}$ the leaves of greenhouse plants (L) and in vitro plantlets (LR); acetone (A) and ethanol (E) extracts of exudate compounds of the leaves ${ }^{b}$ In parentheses is ratio "concentration of the constituent in exudate A or E/its total concentration in the leaf of in vitro plantlets"

In the course of flavonoid composition studying of the leaves of greenhouse plants and in vitro plantlets, as well as the leaf exudates of B. fischeri var. palustris, quercetin glycosides (isoquercitrin, hyperoside), Cglycosyl flavones (vitexin, isovitexin) and free aglycones, quercetin, luteolin and kaempferol (in minute amounts) were found (Table 2). The main constituent of the leaves and the leaf exudates was isoquercitrin.

Numbers of flavonoids in the leaves and leaf exudates slightly varied mainly due to free aglycones and minor C-glycosyl flavones. Minimal number of flavonoids was found in the exudate $\mathrm{E}$, whereas concentrations of the constituents were substantially higher than in exudate $A$. In exudate $A$, number of flavonoids was maximal due to the presence of isovitexin, kaempferol rutinoside, free kaempferol and the others minor compounds.

Proportions of the constituents in the leaves and leaf exudates were also equal. Concentrations of total flavonoids in the leaves of in vitro plantlets were insignificantly lower in comparison with greenhouse plants. Both values were substantial (above 13 and 15 $\mathrm{mg} \cdot \mathrm{g}^{-1}$, respectively). Significant differences were found between the concentrations of isovitexin, hyperoside, isoquercitrin, rutin, kaempferol rutinoside and free quercetin. Flavonoids were more than half of the concentration of total phenolic compounds. Isoquercitrin was about $60 \%$ of total flavonoids concentration.

Concentrations of phenolic compounds in the exudates $\mathrm{A}$ and $\mathrm{E}$ were $<0.02 \mathrm{mg} \cdot \mathrm{g}^{-1}$ and $>2 \mathrm{mg} \cdot \mathrm{g}^{-1}$, respectively. In the exudates A this concentration was $0.08 \%$ and concentration of flavonoids was $0.10 \%$ of their concentration in the leaves as a whole. In the exudates E, comparable percentages were $3.22 \%$ and $9.21 \%$. Certain constituents were extracted with acetone better, for example, free quercetin and kaempferol glycosides. Thereby, extraction of exudate flavonoids with acetone caused the enrichment of the extract by free quercetin and kaempferol glycosides and extraction with ethanol promoted the increase of total flavonoids in the extract of exudate compounds. Some amount of anthocyanins in exudate $\mathrm{E}$ indicates possible extraction of definite amounts of vacuolar constituents.

Despite of some decrease of total flavonoids concentration in the leaves of the in vitro plantlets in comparison with greenhouse plants, the yield of total flavonoids per plant in the plantlets was significantly higher (Table 2).

The examination of antimicrobial properties of the leaf extracts showed that crude extracts of the leaves of B. fischeri var. palustris inhibited growth of seven from nine reference strains (Table 3). Both extracts were active against gram-positive bacteria, $S$. aureus (MICs of $50 \mu \mathrm{g} / \mathrm{mL}$ ), S. pyogenes (MICs of $20 \mu \mathrm{g} \cdot \mathrm{mL}^{-1}$ ) and $B$. subtilis (MICs of 20 and $50 \mu \mathrm{g} \cdot \mathrm{mL}^{-1}$ ), as well as E. aerogenes (MICs of $50 \mu \mathrm{g} \cdot \mathrm{mL}^{-1}$ ). The extract L inhibited the growth of E. coli, E. faecalis and C. albicans (MICs of $50 \mu \mathrm{g} \cdot \mathrm{m} \mathrm{L}^{-1}$ ). None of the extracts showed activity against $K$. pneumonia and $P$. eaeruginosa. 
Table 3: Antimicrobial properties of crude extracts and exudates of the leaves of B. fischeri var. palustris Minimal inhibition concentration, $\mu \mathrm{g} \cdot \mathrm{mL}^{-1}$

\begin{tabular}{|c|c|c|c|c|c|c|c|c|c|}
\hline & SA & SP & BS & $\mathrm{KP}$ & EA & $\mathrm{EC}$ & PA & $\mathrm{EF}$ & $\mathrm{CA}$ \\
\hline Extract L $^{b}$ & 50 & 20 & 20 & $-^{a}$ & 50 & 50 & - & 50 & 50 \\
\hline Extract LR & 50 & 20 & 50 & - & 50 & - & - & - & - \\
\hline Exudate A & - & - & 50 & - & - & - & - & - & - \\
\hline Exudate E & 50 & - & 50 & - & - & - & - & - & - \\
\hline
\end{tabular}

${ }^{\mathrm{a}}$ The absence of activity

${ }^{\mathrm{b}} \mathrm{L}$ - extract from the leaves of greenhouse plants; LR - extract from the leaves of in vitro plantlets; exudates A and E- acetone and ethanol extracts of exudate compounds of the leaves, respectively

Therefore, the spectra of antimicrobial activity of two extracts differed. The spectrum of extract $\mathrm{L}$ from the leaves of greenhouse plants (7 reference strains) was wider than the spectrum of extract LR from the leaves of in vitro plantlets (4 reference strains). Only extract L from the leaves of greenhouse plants was active against $C$. albicans.

Antimicrobial effects of the exudates was reduced. The exudate E exhibited inhibition of the growth of two reference strains of gram-positive bacteria, $S$. aureus and B. subtilis (MICs of $50 \mu \mathrm{g} \cdot \mathrm{mL}^{-1}$ ) and the exudate A inhibited the growth of only one reference strain, $B$. subtilis (MIC of $50 \mu \mathrm{g} \cdot \mathrm{m} \mathrm{L}^{-1}$ ).

\section{Discussion}

The result suggests that a low profile of macro- and micronutrients is effective for the species seed germination. This is consistent with the earlier report of Chamandoosti (2016), where among of different basal media that were evaluated for their effects on sesame seed germination, half strength MS was found to be the best medium for germination.

During the plants establishment in greenhouse, we note that plant status and size of the leaves of in vitro plantlets were higher in comparison to greenhouse plants (Fig. 2b, a, c). The difference in phenolic and flavonoid contents in the leaves reflected the difference in the morphological traits. Thus, the plantlets with more vigorous growth had lower flavonoid content. This corresponds with many reports about increase of flavonoids in the stress or unfavorable conditions (Karpova et al., 2016).

On account to the significantly higher yield of flavonoids per plant and a shorter (by 2-3 months) growing cycle, the in vitro plantlets of $B$. fischeri var. palustris can be regarded as a promising source of flavonoids.

We showed that antimicrobial activity of the extracts of $B$. fischeri var. palustris varied with various flavonoid composition and content. The spectra of antimicrobial activity of the extracts of in vitro plantlets and the exudates were substantially reduced. At the same time, inhibition effect of the extracts on the growth of the strains of B. subtilis and S. aureus manifested in most cases. Unstable inhibition effects of the extracts of plants of $B$. fischeri var. palustris in relation to the strains of $E$. coli, E. faecalis and C. albicans indicates that antimicrobial activity against these pathogens requires higher concentrations of flavonoids. Further works should be designed in order to assess the impact of concentration of the main constituents and some varying components of extracts (quercitrin, free aglycons and kaempferol glycosides) on the antimicrobial action.

Another direction of the study can be dealt with the selection of clones with high flavonoid content. Our results are in accordance with the reports on high flavonoid content of micropropagated plants ( $\operatorname{Rad}$ et al., 2014; Goda et al., 2017), but the level can be increased.

Of great importance are compounds located on the leaf surface. Recently, these compounds are the objectives of new direction of investigations, the metabolic engineering concerning with in vitro synthesis and secretion of large amounts of target compounds by leaf surface structures. The works in this field increase, but at this point, they are still quite fragmentary (Huchelmann et al., 2017). We showed that the flavonoid composition of exudates of $B$. fischeri var. palustris differs slightly from the composition of the leaves as a whole, but the concentrations of most of components are insignificant. This caused a weak antimicrobial activity of exudates. However, the direct contact of the flavonoids of the leaf surface with the air creates the base for antimicrobial properties sufficient to reduce a colony-forming units in the air. This reduction was previously shown in experiments with intact plants in kindergartens and libraries (Fershalova et al., 2018). One of the further directions of the investigation should be the nutritious medium optimization to get a significant increase of exudative flavonoids amounts for high antimicrobial activity (Kim et al., 2015).

Thus, in our study we established an efficient in vitro propagation and regeneration protocol of B. fischeri var. palustris plants, with rich flavonoid content, obtained from the seeds culture, for the aims of interior design and health benefits.

\section{Conclusion}

In our study, we developed the protocol of micropropagation and acclimatization of in vitro plantlets of $B$. fischeri var. palustris with high flavonoid 
content in the leaves (13 $\mathrm{mg} \cdot \mathrm{g}^{-1}$ of dry weight) insignificantly differed from the leaves of the greenhouse plants and with higher yield of total flavonoids per plant (189.1 $\mathrm{g}$ in comparison with $174.0 \mathrm{~g}$ ). The highest percentages of seed germination were revealed in the half strength MS medium (92.5\%) and in 1\% agar medium $(83.3 \%)$. The extract of the leaves inhibited the growth of four from nine reference strains, $S$. aureus (MIC of $20 \mu \mathrm{g} \cdot \mathrm{mL}^{-1}$ ), B. subtilis, S. aureus and E. aerogenes (MICs of $50 \mu \mathrm{g} \cdot \mathrm{mL}^{-1}$ ). Concentrations of flavonoids in acetone and ethanol extracts of exudative compounds of the leaves of in vitro plantlets were 0.02 and $2.0 \mathrm{mg} \cdot \mathrm{g}^{-1}$ of dry weight, respectively. These extracts inhibited the growth of one (B. subtilis) and two reference strains (B. subtilis and $S$. aureus). The in vitro derived $B$. fischeri var. palustris plants are promising for indoor design of children institution and public places and for air cleaning. The purpose of further investigation is the improvement of culture conditions for the production of plants with genetically stable high level of flavonoid content.

\section{Funding Information}

The work was financially supported by the publicly funded project of the CSBG SB RAS “Assessment of the morphogenetic potential of North Asian plant populations by experimental methods" (No. AAAAA17-117012610051-5) within the framework of a government contract and with material of CSBG representing USFs (Unique Scientific Facilities) "Collections of living plants indoors and outdoors" USU 440534 with partial support by research grant \# 17-44540601 from the Russian Foundation of Basic Research and partial support by a Russian government-funded project (VI.62.2.2, 0309-2016-0007).

\section{Authors' Contributions}

Evgeniya A. Karpova: Designed the study, performed the HPLC, the statistical analyses and wrote the manuscript.

Alexandra Yu. Nabieva: Performed in vitro seed germination and the statistical analysis, maintained seedlings cultures, wrote the protocol and wrote the manuscript.

Tatiana D. Fershalova: Conducted the acclimatization of the regenerants and wrote the manuscript.

Yuliya L. Yakimova and Natalya V. Tsybulya: Performed the evaluation of antimicrobial activity. All authors read and approved the final manuscript.

\section{Conflict of Interest}

The authors declare that they have no conflict of interest.

\section{References}

Andrews, J.M., 2001. Determination of minimum inhibitory concentrations. J. Antimicrobial Chemotherapy, 48: 5-16.

Arendrup, M.C., J. Meletiadis, J.W. Mouton, K. Lagrou and P. Hamal, J. Guinea, 2017. Method for the determination of broth dilution minimum inhibitory concentrations of antifungal agents for yeasts. EUCAST definitive document E.DEF 7.3.1.

Chamandoosti, F., 2016. Influence of plant growth regulators and explant type on multiple shoot induction and somatic embryogenesis in sesame (Sesamum indicum L.). Int. J. Environ. Agric. Res., 2: 68-72.

Chirol, N. and M. Jay, 1995. Acylated anthocyanins from flowers of Begonia. Phytochemistry, 40: 275-277. DOI: 10.1016/0031-9422(95)00073-G

Cushnie, T.P.T. and A.J. Lamb, 2005. Antimicrobial activity of flavonoids. Int. J. Antimicrobial Agents, 26: 343-356.

Ensemeyer, M. and L. Langhammer, 1982. Two lipophilic flavonoids from Begonia glabra. Planta Medica, 46: 254-255. DOI: 10.1055/s-2007-971229

Fershalova, T., E. Baikova and A. Ushakova, 2018. Application of phytoncidal plants for improvement of ecological parameters of the air of library interiors. Proceedings of the IV(VI ${ }^{\text {th }}$ All-Russia Scientific-Practical Conference "Prospects of Development and Challenges of Modern Botany". Aug. 21, BIO Web of Conferences, Russia. DOI: $10.1051 /$ bioconf $/ 20181100014$

Frei, B., M. Heinrich, D. Herrmann, J.E. Orjale and J. Schmitt et al., 1998. Phytochemical and biological investigation of Begonia heracleifolia. Planta Medica, 64: 385-386. DOI: 10.1055/s-2006-957460

Goda, S.M., S.A. Ahmed, F. El Sherif, H.A. Hassanean and A.K. Ibrahim, 2017. Genetically stable plants with boosted flavonoids content after in vitro regeneration of the endangered Capparis spinosa L. Glob Drugs Therap., 2: 3-7.

DOI: $10.15761 /$ GDT.1000124

Harborne, J.B. and C.A. Williams, 2001. Anthocyanins and other flavonoids. Natural Product Reports, 18: 310-333. DOI: 10.1039/B006257J

Huchelmann, A., M. Boutry and C. Hachez, 2017. Plant glandular trichomes: Natural cell factories of high biotechnological interest. Plant Physiol., 175: 6-22. DOI: $10.1104 / p p .17 .00727$

Karakulov, A.V., E.A. Karpova and V.G. Vasiliev, 2018. Ecological and geographical variation of morphometric parameters and flavonoid composition of Rhododendron parvifolium. Turczaninowia, 21: 133-144.

DOI: 10.14258/turczaninowia.21.2.14 
Karpova, E.A. and T.D. Fershalova, 2016. Dynamics of leaf pigments content of Begonia grandis Dryander subsp. grandis introduced in West Siberia (Novosibirsk). Tomsk State University J. Biology, 1: 140-158. DOI: $10.17223 / 19988591 / 33 / 9$

Karpova, E.A., A.A. Krasnikov and T.D. Fershalova, 2018. Exometabolites of the representatives of the genus Begonia and its antimicrobial properties. Proceedings of 10th International Symposium "Phenolic compounds: Fundamental and Applied Aspects", May 14-19, Moscow, pp: 288-292.

Karpova, E.A., T.D. Fershalova and A.A. Petruk, 2016. Flavonoids in Adaptation of Begonia grandis Dryander subsp. grandis Introduced in West Siberia (Novosibirsk). J. Stress Physiol. Biochem., 12: 44-56.

Kim, H.J., D.J. Hinchliffe, B.A. Triplett, Z.J. Chen and D.M. Stelly et al., 2015. Phytohormonal networks promote differentiation of fiber initials on preanthesis cotton ovules grown in vitro and in Planta. PLoS ONE, 10: e0125046.

DOI: 10.1371/journal.pone.0125046

Murashige, T. and F. Skoog, 1962. A revised medium for rapid growth and bioassays with tobacco tissue cultures. Physiologia Plantarum, 15: 473-497. DOI: $10.1111 /$ j.1399-3054.1962.tb08052.x

Muravnik, L.E., O.V. Kostina and A.L. Shavarda, 2016. Glandular trichomes of Tussilago farfara (Senecioneae, Asteraceae). Planta, 244: 737-752. DOI: $10.1007 / \mathrm{s} 00425-016-2539-x$

Murugan, K., J.M. Aswathy and K.V. Dinesh Babu, 2016. In vitro seeds germination and seedling growth of Begonia malabarica Lam. (Begoniaceae) a Source for Anthocyanin. Gavin Publishers.
Nisha, S., I. Renuka and P.K. Dharma, 2016. Pharmacognostic, phytochemical, antioxidant and antibacterial activity studies on Begonia picta. World J. Pharmaceutical Res., 5: 979-997.

Rad, F.A., M. Jafari, N. Khezrinejad and M.P. Miandoab, 2014. An efficient plant regeneration system via direct organogenesis with in vitro flavonoid accumulation and analysis of genetic fidelity among regenerants of Teucrium polium L. Horticulture Environ Biotechnol., 55: 68-577. DOI: $10.1007 / \mathrm{s} 13580-014-0611-7$

Ramesh, N., M.B. Viswanathan, A. Saraswathy, K. Balakrishna and P. Brindha, 2002. Phytochemical and antimicrobial studies of Begonia malabarica. J. Ethnopharmacology, 79: 129-132. DOI: $10.1016 / \mathrm{S} 0378-8741(01) 00352-\mathrm{X}$

Saffidine, K., N. Chirol, F. Benayache and M. Jay, 2017. Characterization and distribution of flavonoids from flowers in different horticultural types of Begonia. Pharmacognosy J., 9: 850-855. DOI: $10.5530 / \mathrm{pj} .2017 .6 .133$

Xie, Y., W. Yang, F. Tang, X. Chen and L. Ren, 2015. Antibacterial activities of flavonoids: Structureactivity relationship and mechanism. Current Medicinal Chemistry, 22: 132-149.

DOI: $10.2174 / 0929867321666140916113443$ 